\title{
A Triband U- Slot Patch Antenna with Enhanced Bandwidth and Isolation for MIMO Systems
}

\author{
P. Kiran ${ }^{1}$, R. Chiramjeevi ${ }^{1}$, T. Chaitanya Reddy ${ }^{1}$, D. Sushma Sree ${ }^{1}$ \\ B. V. V. Ravindra Babu ${ }^{2}$ and K. Jagadeesh $\mathrm{Babu}^{3}$ \\ ${ }^{1}$ Students of Dept of ECE, SACET, Chirala, AP, India \\ ${ }^{2}$ Assoc. Professor in ECE, SACET, Chirala, AP, India \\ ${ }^{3}$ Professor \& Head of the Dept ECE, SACET, Chirala, AP, India \\ pusulurikiran@gmail.com
}

\begin{abstract}
The paper presents a compact tri band U slot microstrip patch antenna. The proposed antenna resonates at triband of $3.7 \mathrm{GHz}, 5.8 \mathrm{GHz}$ and $7.1 \mathrm{GHz}$ frequencies for VSWR $\leq 2.5$ with an improved impedance bandwidth of $42 \%$ and a reduced mutual coupling of $-23 d B$ and the antenna is modified by using a shorting pin giving an improved bandwidth of $54 \%$ and isolation of $-28 \mathrm{~dB}$ which antenna resonates at tri band of $3.2 \mathrm{GHz}, 3.7 \mathrm{GHz}$ and $6.4 \mathrm{GHz}$ frequencies for VSWR $\leq$ 1.6.The proposed antenna is a better choice for $4 G$, WLAN,Wi-MAX and Ultra Wide Band applications involving MIMO technique.
\end{abstract}

Keywords: U-slot patch antenna, tri-band, Impedance bandwidth, Mutual coupling

\section{Introduction}

Microstrip or patch antennas are most preferred antennas because they can be printed directly onto a circuit board. Microstrip antennas are becoming very popular within the mobile phone market these antennas are low cost, have a low profile and are easily fabricated. The major disadvantage of microstrip antennas is their low bandwidth. The U shaped patch antennas gained popularity due to their wideband nature. In 1995 a broad band single layer probe fed patch antenna with a u-shaped slot was presented by Huynh and Lee [1] and [2]. However, the general microstrip antennas suffer from narrow bandwidth, which limits their application in modern communication systems like MIMO. Recently, tri-band antennas gained attention as they can be used for various applications including Wi Max [3].

MIMO technology gained popularity in wireless communications as they offer significant data throughput and link range without additional bandwidth or increased transmit power. Also they achieve array gain that improves the spectral efficiency and diversity gain that improves the link reliability with reduced fading. Because of these properties, MIMO is an important part of modern wireless communication standards such as IEEE 803.11 in (WiFi), 4G, 3GPP Long Term Evolution, Wi-MAX and HSPA+.

The main parameter regarding MIMO systems is mutual coupling, which depends on the distance between the elements in a MIMO system. If the distance is more, the mutual coupling between antennas becomes less and vice versa. Hence, by increasing the distance between the elements we can reduce the mutual coupling between the antennas. However, the distance between the antennas cannot be maintained too large, since MIMO systems have their major applications in Mobile terminals, laptops, and WLAN Access Points Wireless communications [4], where size of the device can't be maintained too large. The main source 
of mutual coupling is surface current flowing through ground in order to reduce these, there are several techniques like Electromagnetic band gap structure, defected ground structure [5, 6], decoupling techniques, etc... However, all these methods make the design of the antenna entangled.

In the present work, a $\mathrm{U}$ slot patch antenna is proposed with improved bandwidth and reduced mutual coupling.The designed antenna resonates at a tri-band of $3.7 \mathrm{GHz}, 5.8 \mathrm{GHz}$, and $7.1 \mathrm{GHz}$ frequencies with an improved impedance bandwidth of $42 \%$.

\section{Antenna Design}

The main objective of the antennas used in MIMO systems is to improve the bandwidth of the patch antenna. The dielectric constant of the substrate decides the bandwidth of the microstrip antennas. Low dielectric constant of the substrate produces larger bandwidth, while high dielectric constant of the substrate results in smaller size and low bandwidth [4]. The bandwidth of microstrip antennas can be increased by several techniques such as keeping parasitic elements on the patches, increasing the substrate thickness, inserting slots and using defected ground structures [6].

The patch antennas are fabricated with various shapes and most of them are widely designed antennas are $\mathrm{E}$ shaped patch antenna, $\mathrm{H}$ shaped patch antenna [7], etc. Among all these antennas, E shaped patch antennas are widely used as they give better performance in terms of both impedance bandwidth and mutual coupling. The U-slot patch antenna can be formed by cutting three rectangular slots on a rectangular patch as shown in Figure 1. The dimensions of the geometry are given in the Table 1 . Here the whole system is fed by a coaxial probe at the position $(\mathrm{X} 0, \mathrm{Y} 0)=(5 \mathrm{~mm}, 5 \mathrm{~mm})$. The area of the proposed antenna is $60 \times$ $40 \mathrm{~mm}^{2}$. In [8], the feed position is kept at the center of U-slot, whereas in the present work the feed is kept at one of the corners of the antenna as shown in Figure 1, giving an improvement in the impedance bandwidth.

For better performance, a thick dielectric substrate having a low dielectric constant is desirable as it provides better efficiency, larger bandwidth and better radiation.
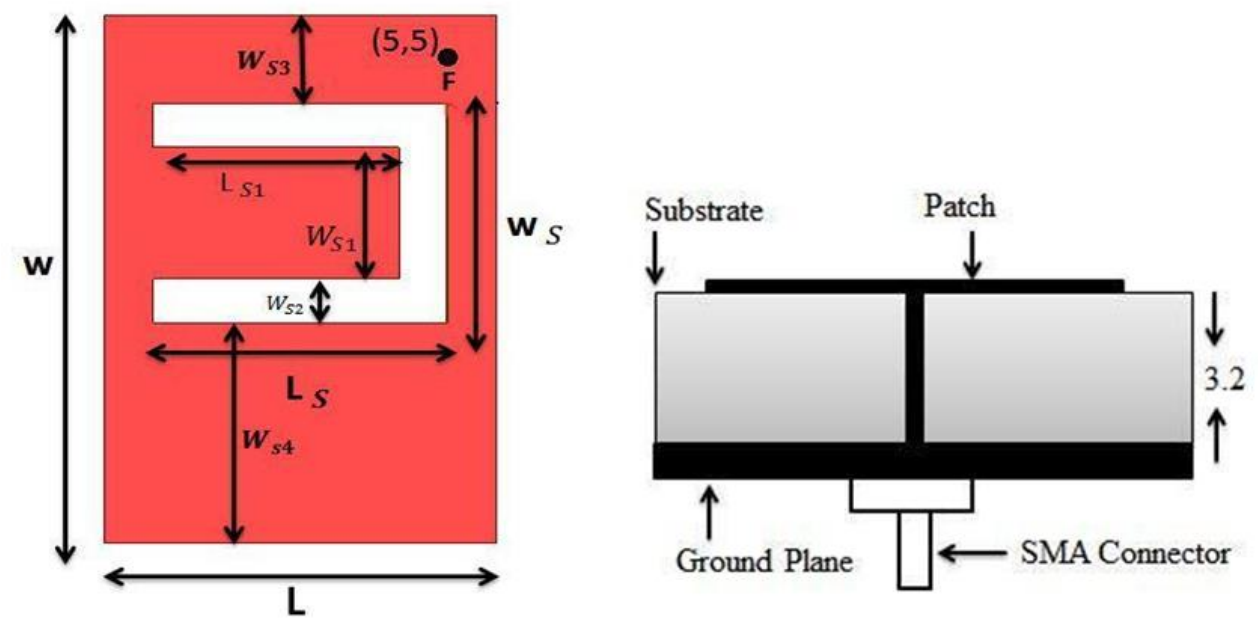

Figure 1. The top and side views of the Proposed U-slot patch antenna 
Table 1. The dimensions of the patch and substrate

\begin{tabular}{|c|c|c|c|c|c|c|c|c|c|}
\hline $\begin{array}{l}\text { Parameters } \\
\text { in (mm) }\end{array}$ & $W$ & $L$ & $\mathrm{~W}_{\mathrm{S}}$ & $\mathrm{W}_{\mathrm{S} 1}$ & $\mathrm{~W}_{\mathrm{S} 2}$ & $\mathrm{~W}_{\mathrm{S} 3}$ & $\mathrm{~W}_{\mathrm{S} 4}$ & $\mathrm{~L}_{\mathrm{S}}$ & $\mathrm{L}_{\mathrm{S} 1}$ \\
\hline Values(mm) & $\mathbf{6 0}$ & $\mathbf{4 0}$ & $\mathbf{2 5}$ & $\mathbf{1 5}$ & $\mathbf{2 5}$ & $\mathbf{1 0}$ & $\mathbf{2 5}$ & $\mathbf{3 0}$ & $\mathbf{2 5}$ \\
\hline
\end{tabular}

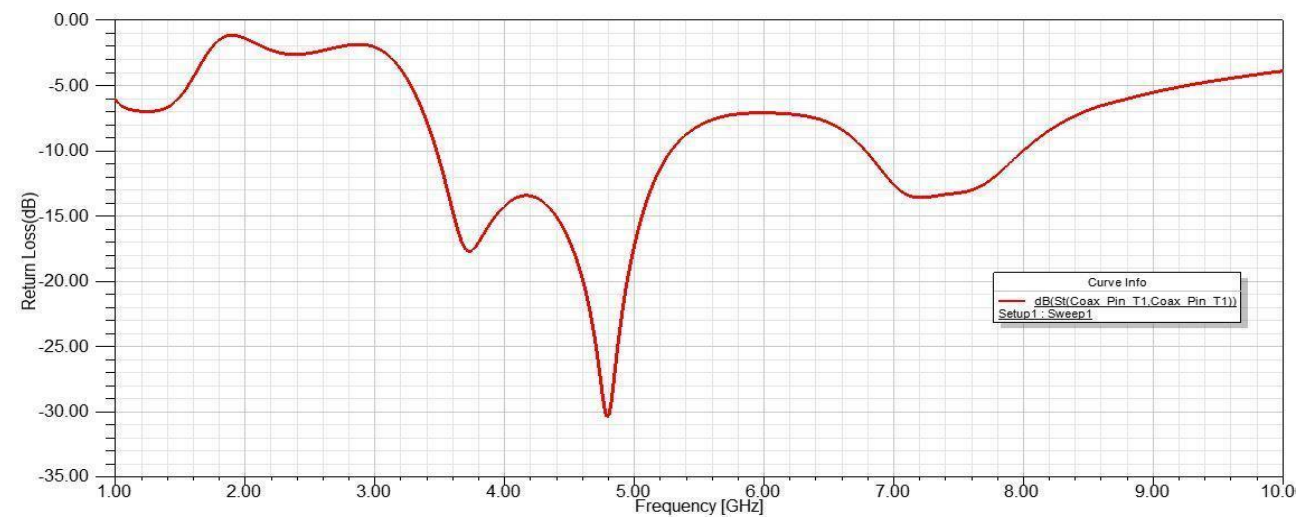

Figure 2. The return loss of the proposed antenna

Here, the substrate selected for the design of the proposed antenna is verified by using different materials such as Epoxy Kevlar, FR4_epoxy, Air and RT/duroid®5880 and among all these parameters Air substrate produces high impedance bandwidth as shown in Table 2 and the return loss plot is sown in Figure 3 As the dielectric constant of the material decreases then the bandwidth will increase we can observe in the Table 2. Figure 2 shows the return loss plot of different materials with a dielectric constant ranges from 1to 4.4.

Table 2. Different bandwidths obtained for different materials

\begin{tabular}{|c|c|c|c|}
\hline S.NO & Material & $\begin{array}{c}\text { Dielectric } \\
\text { constant }\end{array}$ & $\begin{array}{c}\text { Impedance } \\
\text { Band Width }\end{array}$ \\
\hline 1) & Air & 1 & $42 \%$ \\
\hline 2) & $\begin{array}{c}\text { Rogers } \\
\text { RT/Duroid 5880 }\end{array}$ & 2.2 & $35 \%$ \\
\hline 3$)$ & Epoxy & 3.6 & $24 \%$ \\
\hline 4$)$ & FR4 epoxy & 4.4 & $10 \%$ \\
\hline
\end{tabular}




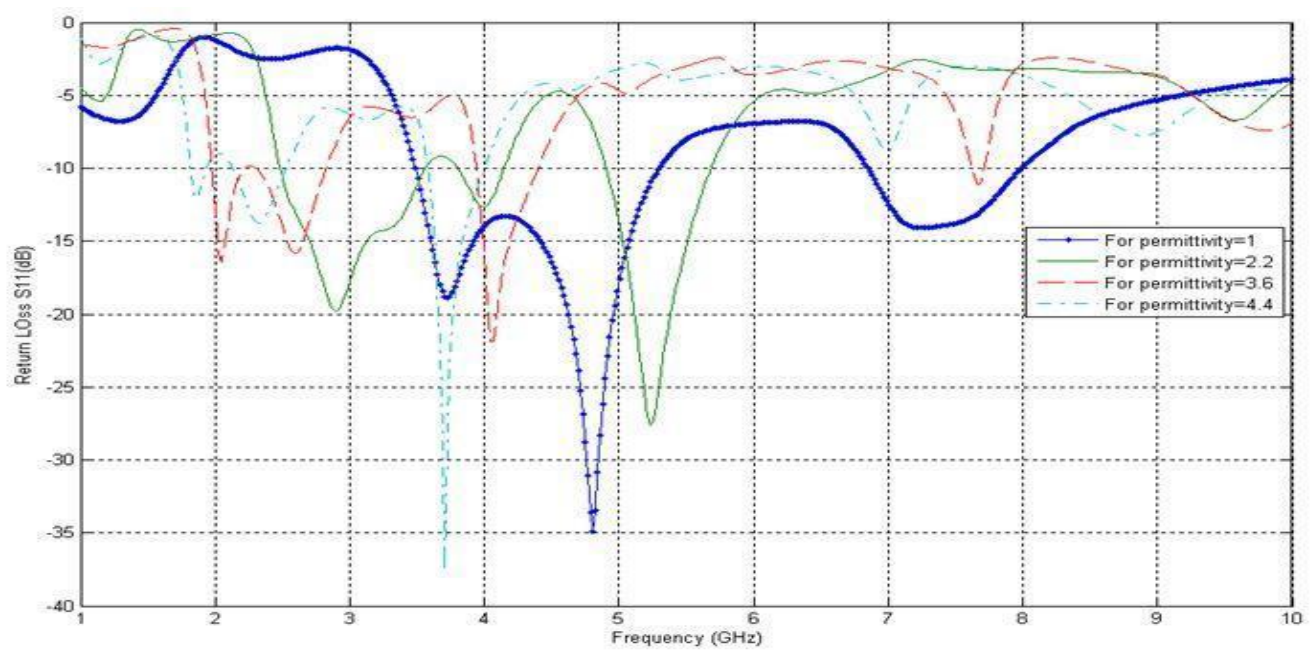

Figure 3. The return loss plot of Different bandwidths obtained for different materials

\section{A Two Element MIMO System}

Equalization is a captious aspect for wireless communication systems. Using multi antenna at both transmit and receive ends, which are referred to as MIMO, have been considered as a promising scheme to increase system capacity. Without increasing the distance between the elements the mutual coupling can be minimized by using diversity techniques as explained in [8].

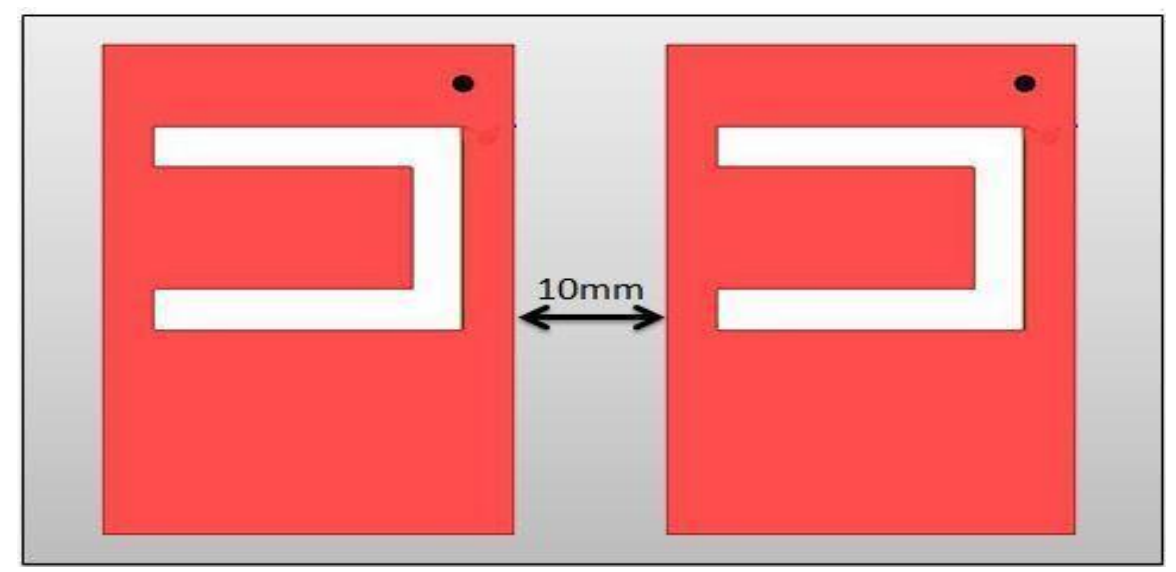

Figure 4. (a) A two element MIMO system using proposed U-slot antenna

A Shorting pin can be acts as feed to the patch; we all think that pin may zero power delivered to the antenna. But the patches are high frequencies which are in the order of $\mathrm{GHz}$ actually the pin causes the inductance between patch and the substrate

The affect of the two parallel plates will shifts the resonant frequency of the antenna. In particular, the two components are in parallel would result in their admittances $(Y=1 / Z)$ adding. Hence, the admittance of the patch has a $1 /(\mathrm{ja})$ added to it. In this manner, the resonant frequency can be shifts. 


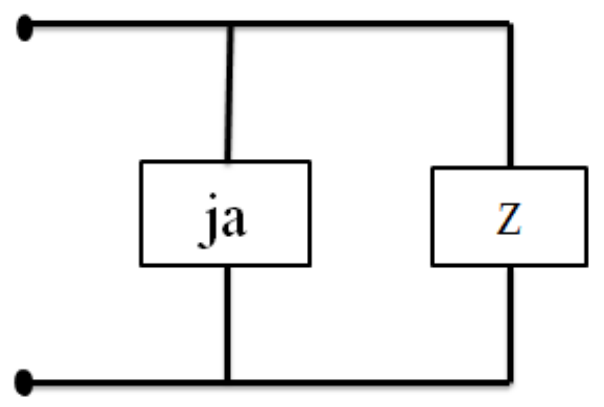

\section{Figure 4. (b) Equivalent circuit of the above single antenna}

In addition, the shorting pin can creates capacitive if instead of extending all the way to the ground plane, it is left floating a small amount above. This introduces another design parameter when compared to the above antenna without the shorting pin. This shows improvement in bandwidth and isolation and it resonates at three different frequencies 3.2 $\mathrm{GHz}, 3.7 \mathrm{GHz}$ and $6.4 \mathrm{GHz}$ as shown in Figure 11 we can observe it.

Above Figure 4 represents the two element MIMO system mainly when two antennas are side by side in the above fashion there will be coupling on one another the best example is inductors placed side by side with some input source. That is nothing but mutual coupling but it should be very less it mean that is performing better performance.

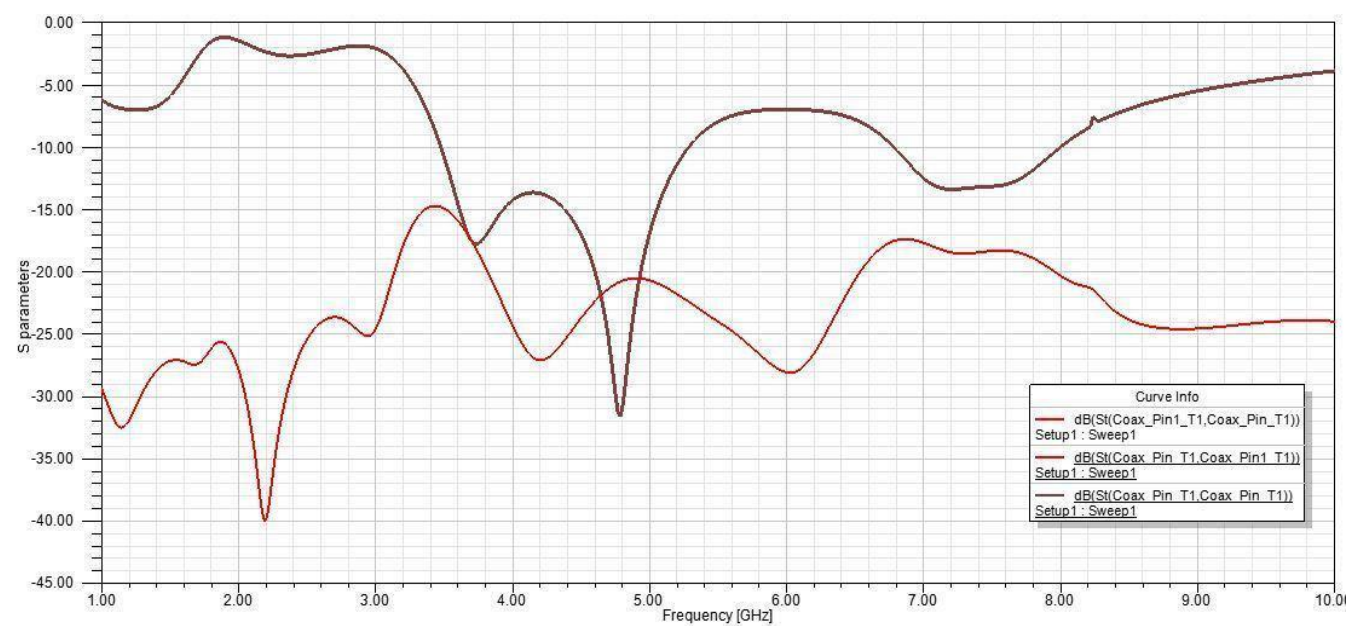

Figure 5. S parameters of proposed U-slot microstrip patch antenna

The return loss of single antenna and their corresponding resonant frequencies and isolation of $2 \times 2$ MIMO systems are given in Table 3. Mutual coupling happen in any high frequency structures when they are exposed to each other. When Mutual coupling of the antenna must be as low as possible otherwise it causes interference in the signal and may cause effect on signal strength [6].

The Figure 5 shows the simulated results of return loss and the mutual coupling. The system resonates a triband $4.2 \mathrm{GHz}, 5.96 \mathrm{GHz}, 7 \mathrm{GHz}$, with an improved impedance 
bandwidth of $42 \%$ ( $9 \mathrm{GHz}$ to $12.7 \mathrm{GHz}$ ) and the obtained mutual coupling between the antenna elements is small and is less than $-28 \mathrm{~dB}$. Also, the obtained bandwidth by using the proposed antenna is very high compared to the normal E shaped patch antenna [6].

Table 3. Results obtained for the proposed antenna

\begin{tabular}{|c|c|c|c|}
\hline S.NO & $\begin{array}{l}\text { Resonant } \\
\text { frequency(GHz) }\end{array}$ & $\begin{array}{c}\text { Return Loss } \\
(\boldsymbol{d B})\end{array}$ & $\begin{array}{c}\text { Isolation } \\
(\boldsymbol{d B})\end{array}$ \\
\hline 1$)$ & 3.7 & -12.3 & -15 \\
\hline 2$)$ & 5.8 & -24 & -20 \\
\hline 3$)$ & 7.1 & -18 & -30 \\
\hline
\end{tabular}

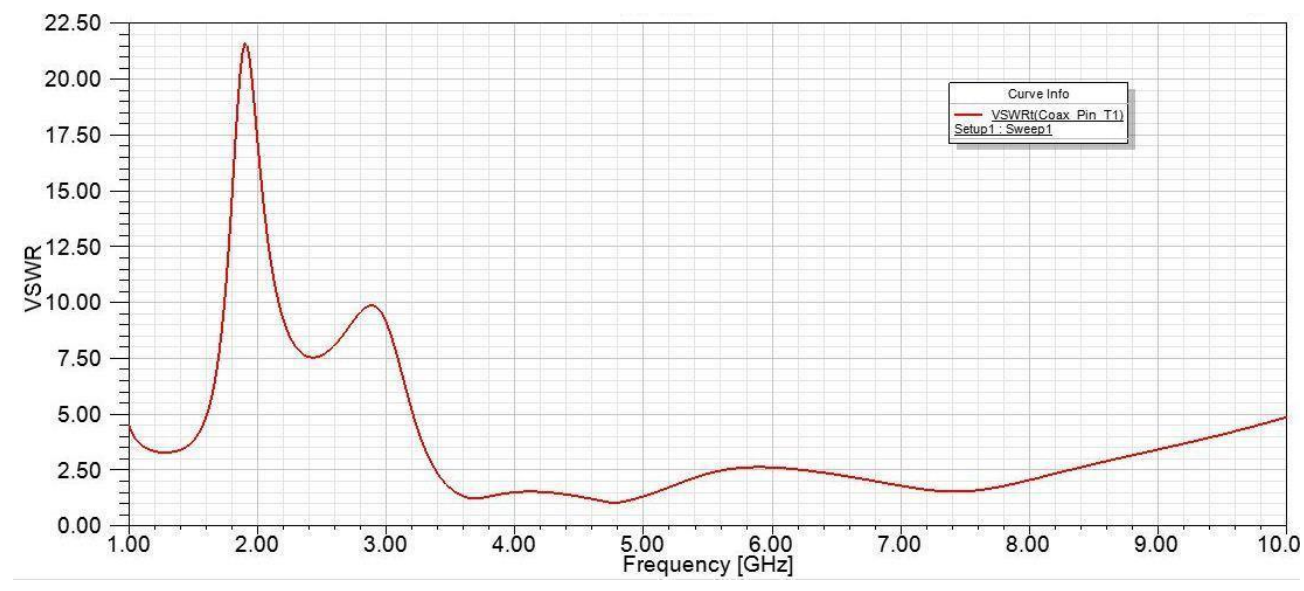

Figure 7. VSWR plot of the proposed Antenna

The VSWR plot of the proposed MIMO array is presented in the Figure 7. The plot gives the desired values of VSWR at the resonant frequencies, which are less than 1.6. The VSWR value is observed as at the resonant respectively, indicating improved matching conditions. The Figure 8 shows the obtained radiation Patterns of the proposed antenna. The Figure 7 shows the gain plot of the proposed antenna. 


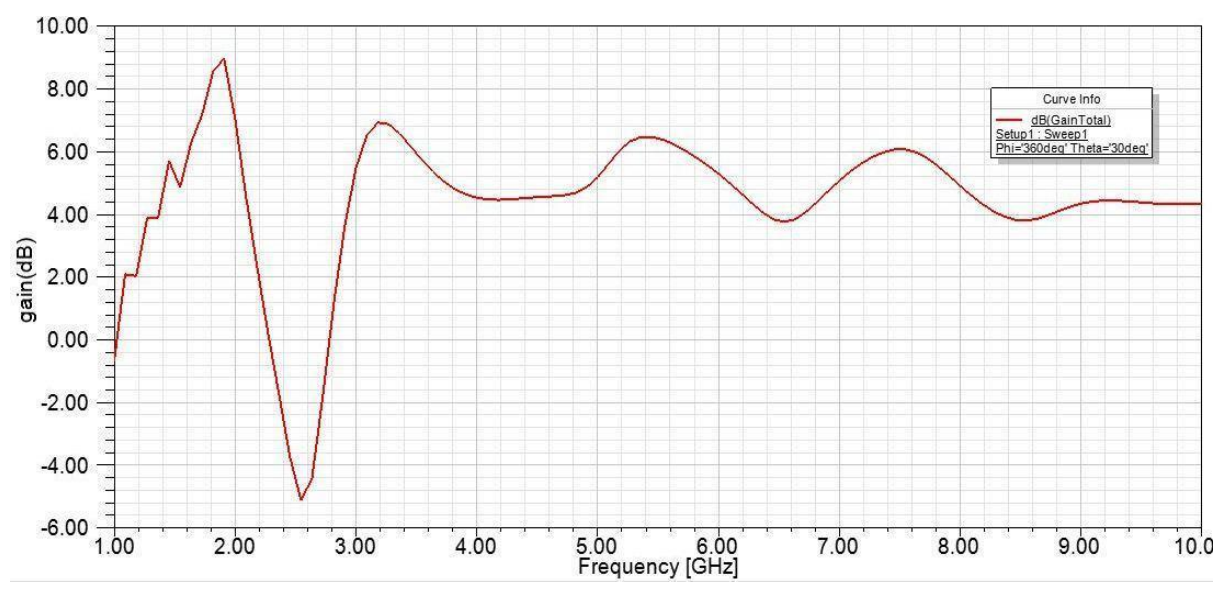

Figure 7. Gain plot of the proposed Antenna

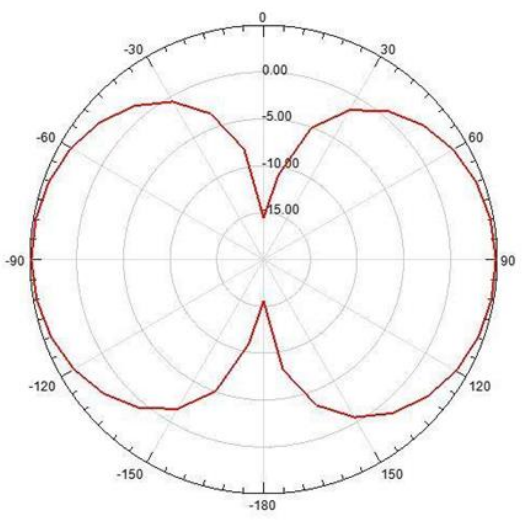

(a) $3.7 \mathrm{GHz}$

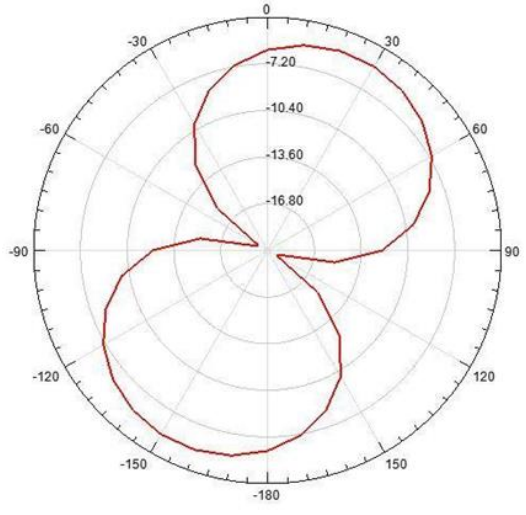

(b) $5.8 \mathrm{GHz}$

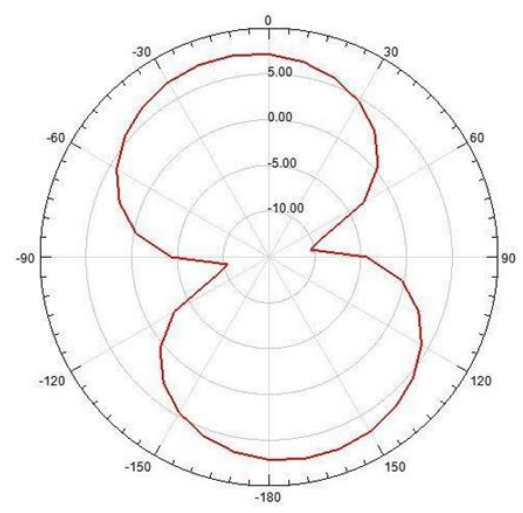

(c) $7.1 \mathrm{GHz}$

Figure 8. Radiation patterns of the proposed antenna

The variation of power radiated by the proposed antenna at triple band are shown here. 


\section{U-Slot Patch Antenna with a Shorting Pin}

A schematic of a microstrip antenna with probe feed and a shorting pin is shown in Figure 9(b). The probe feed is described by its radius $1.6 \mathrm{~mm}$ and is located at $(5,5)$. The shorting pin has radius $0.58 \mathrm{~mm}$ and is located at $(5,16)$. The rectangular $U$ slot patch antenna is described by the dimensions $60 \times 40^{2}$ as mentioned in Table 1 .

To improve the performance one method used in patch antenna design is to introduce shorting pins (from the patch to the ground plane) at various locations. By measuring the characteristics of the proposed antenna with shorting pin, by this there is a increment in band width as well as isolation when compared to [8] in the order of $54 \%$ and $-28 \mathrm{~dB}$.

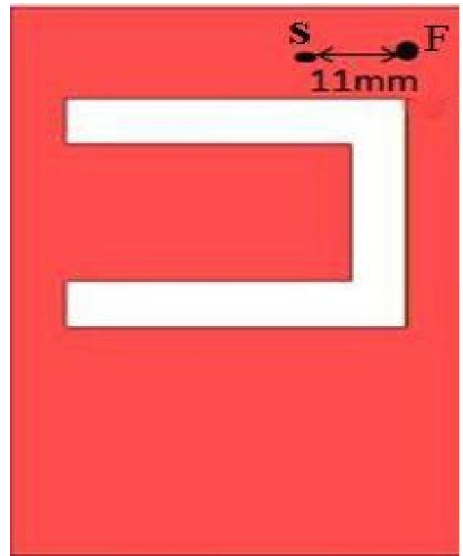

(a) Top view of the antenna.

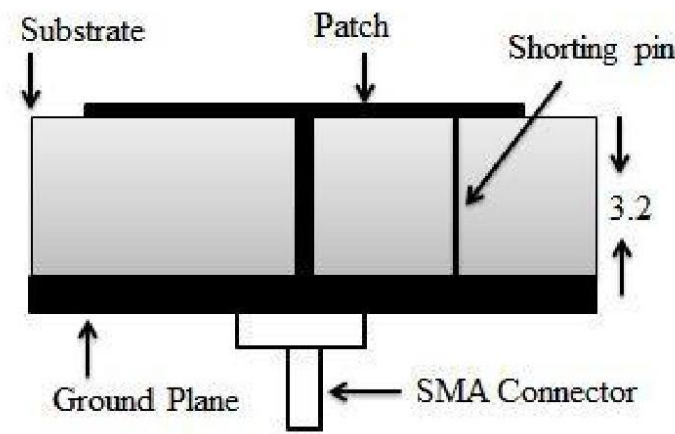

(b) Side view of the antenna.

Figure 9. The dimensions of the U-slot patch antenna in millimeters; letter "F" is the feed point and $S$ is the shorting pin

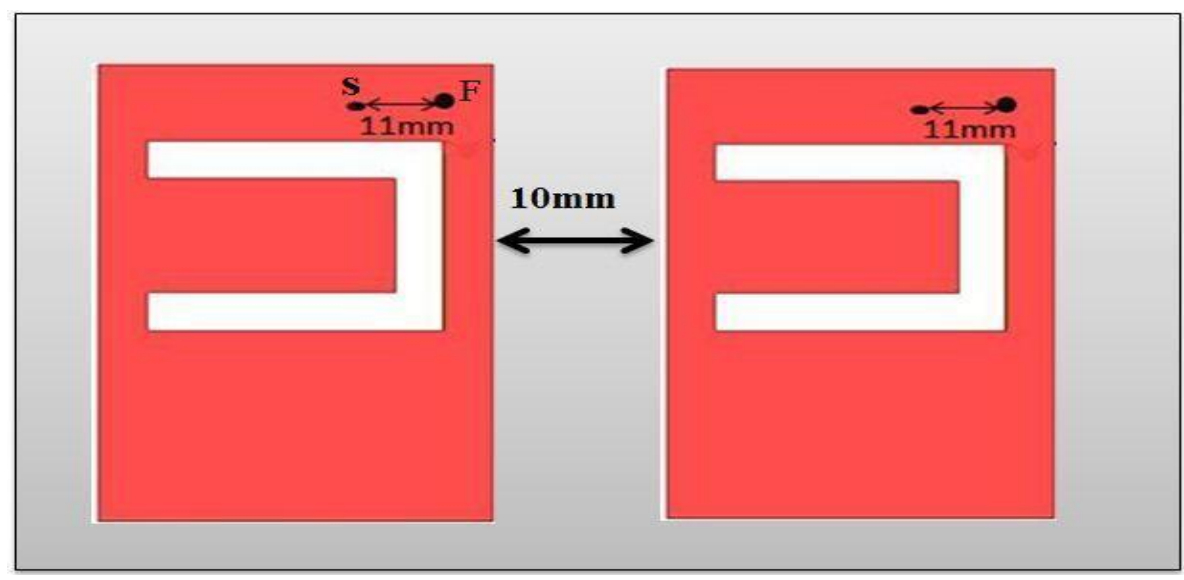

Figure 10. A two element MIMO system using proposed U slot antenna 


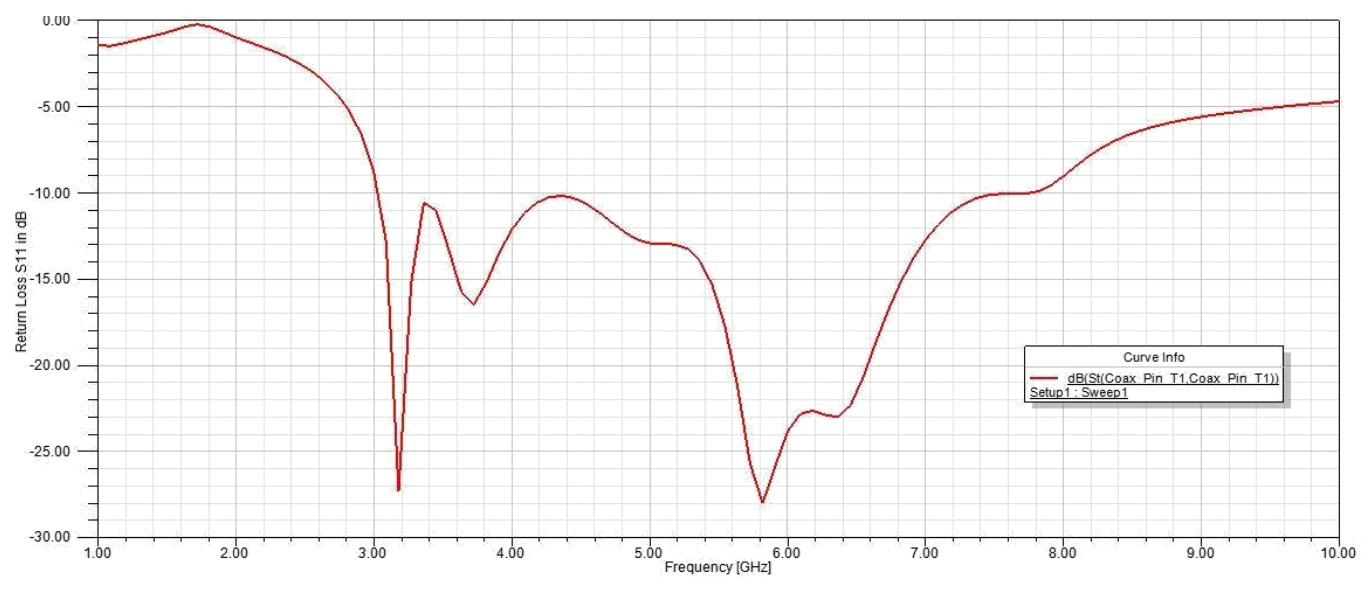

Figure 11. The return loss plot of antenna with the U-slot and shorting pin

For the design of this antenna, the substrate Air of thickness $3.2 \mathrm{~mm}$ and with low permittivity $(\varepsilon \mathrm{r}=1)$ value is selected. The proposed $U$ slot patch antenna gives an improved bandwidth from $42 \%$ to $54 \%$ and an improved return loss. The reason for the improvement in the bandwidth is due to the by introducing the shorting pin from patch to ground plan. The proposed antenna resonates at the three frequencies $3.2 \mathrm{GHz}, 3.7 \mathrm{GHz}$ and $6.4 \mathrm{GHz}$ as shown in Figure 11.

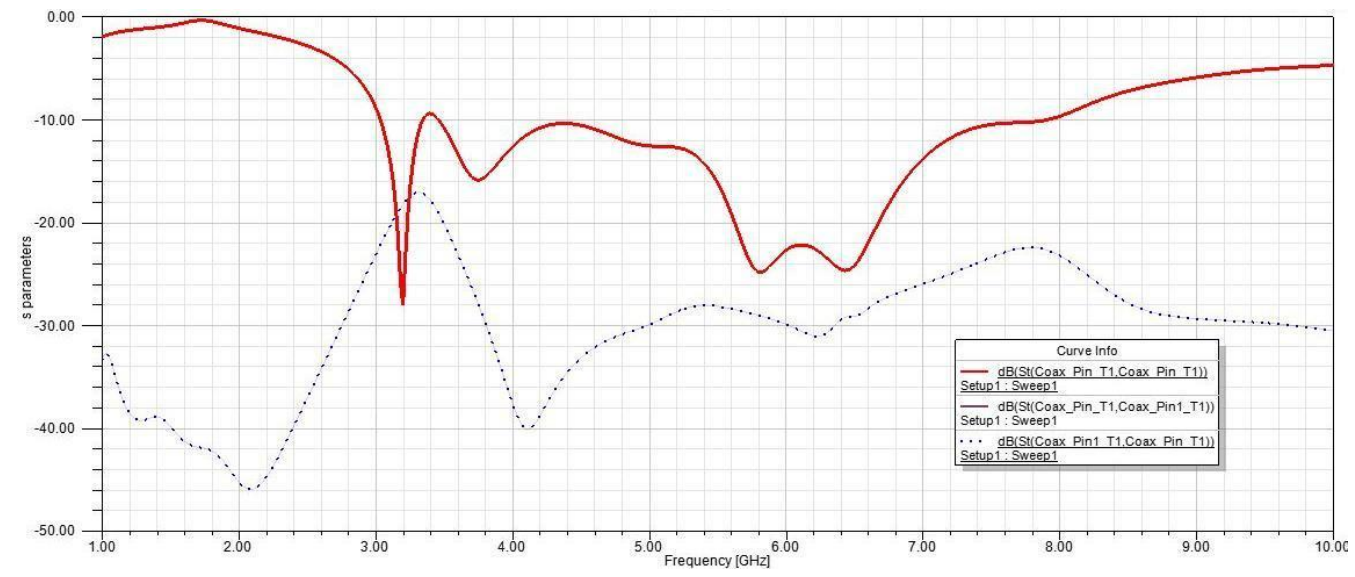

Figure 12. S parameters of proposed U slot microstrip patch antenna with shorting pin

The results are presented in the Figure 12. From the results it is observed that the proposed MIMO array exhibits improved return loss (S11) and excellent isolation properties (S12) at the resonant frequencies $3.2 \mathrm{GHz}, 3.7 \mathrm{GHz}$ and $6.4 \mathrm{GHz}$. The antenna gives the $-10 \mathrm{~dB}$ bandwidth of 54\%. The important parameter to be considered in the design is mutual coupling $\mathrm{S} 12$ which is $<-28 \mathrm{~dB}$ at $3.7 \mathrm{GHz}$ resonant frequencies. This low value of mutual coupling suggests the proposed array system to be an efficient system in terms of isolation [6]. 
International Journal of Energy, Information and Communications Vol.4, Issue 5 (2013)

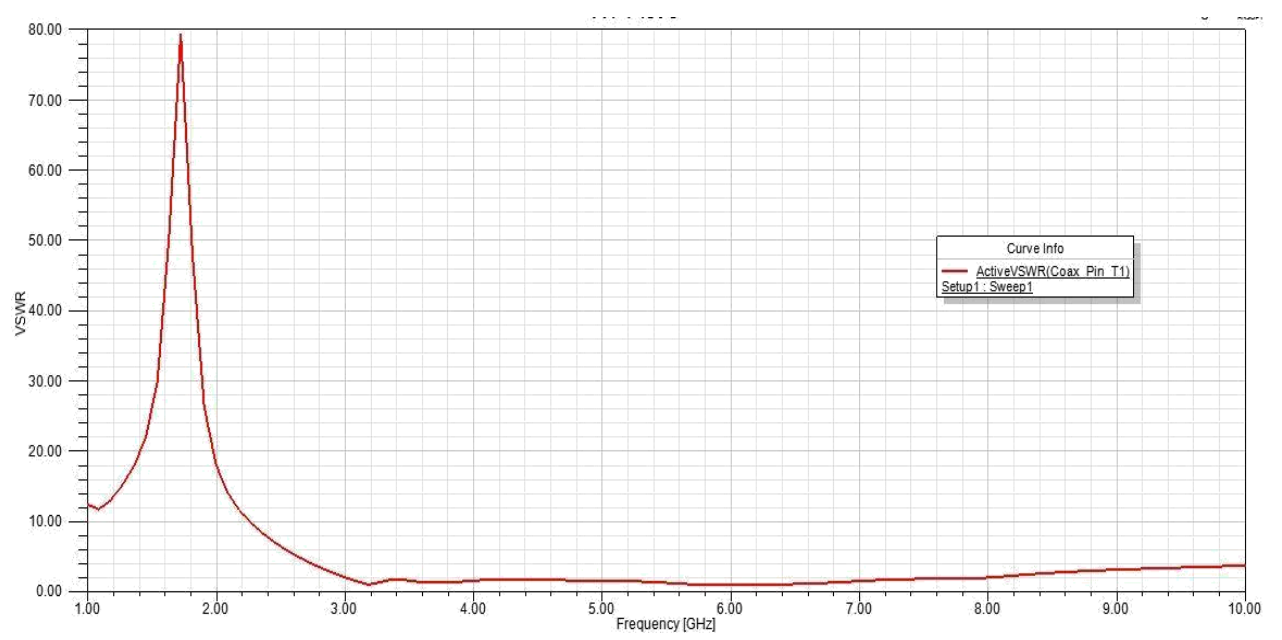

Figure 13. VSWR plot of the proposed Antenna

The VSWR plot of the proposed MIMO array is presented in the Figure 13. The plot gives the desired values of VSWR at the resonant frequencies, which are less than 1.6. The VSWR value is observed as at the resonant are 1.4, 1.3and 1.1 respectively, indicating improved matching conditions. The Figure 13 shows the obtained radiation Patterns of the proposed antenna. The Figure 14 shows the gain plot of the proposed antenna.

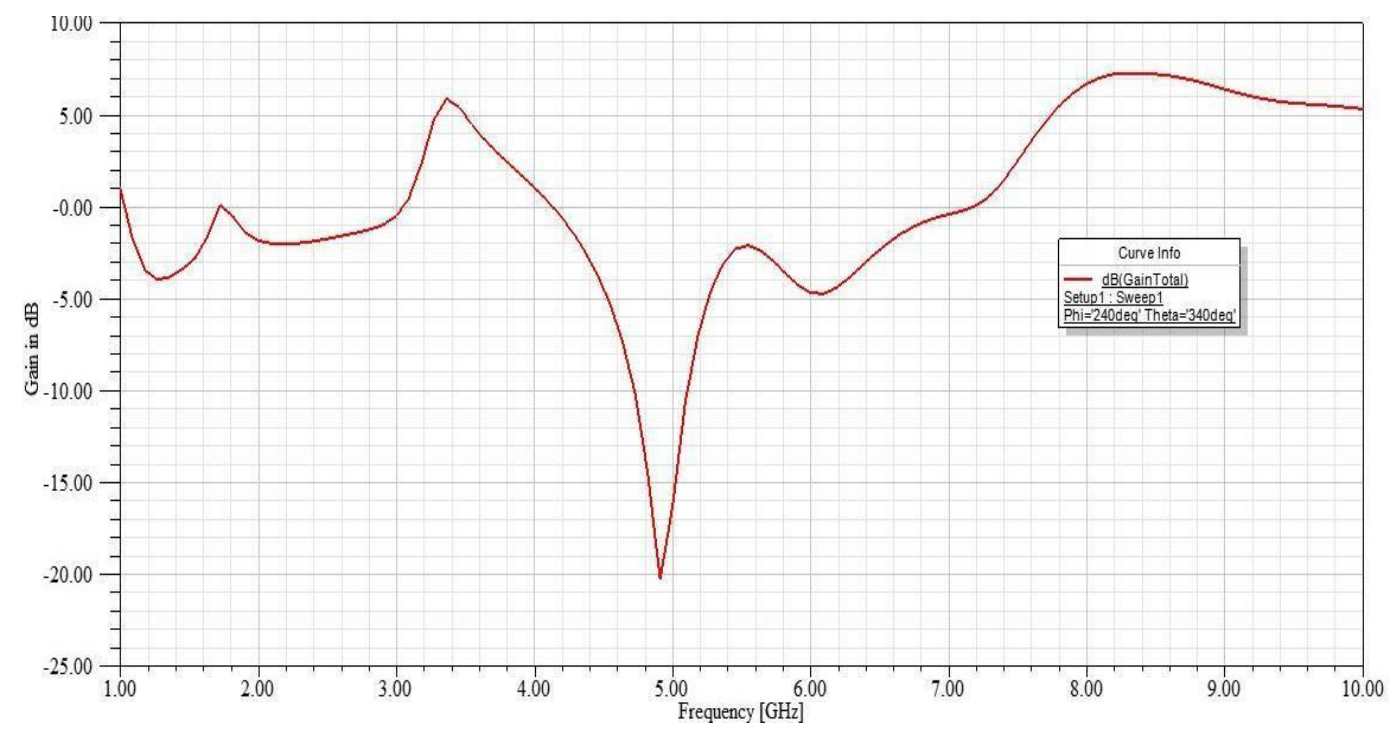

Figure 14. Gain plot of the proposed Antenna 


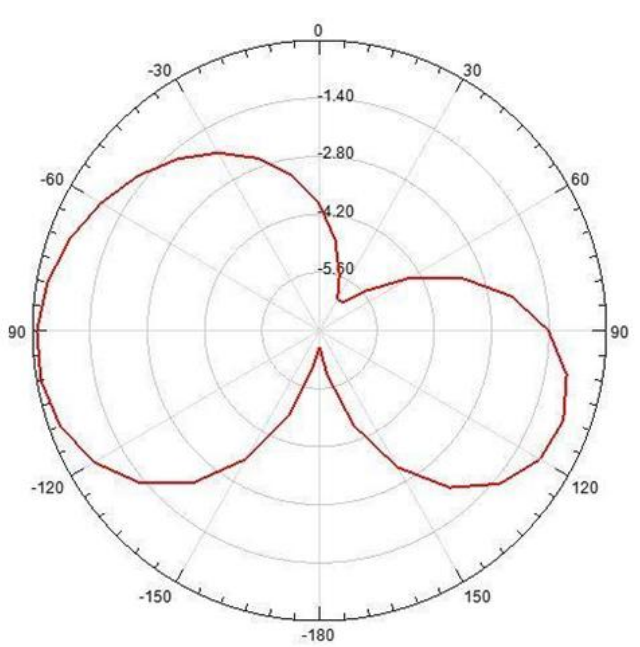

(a) $3.2 \mathrm{GHz}$

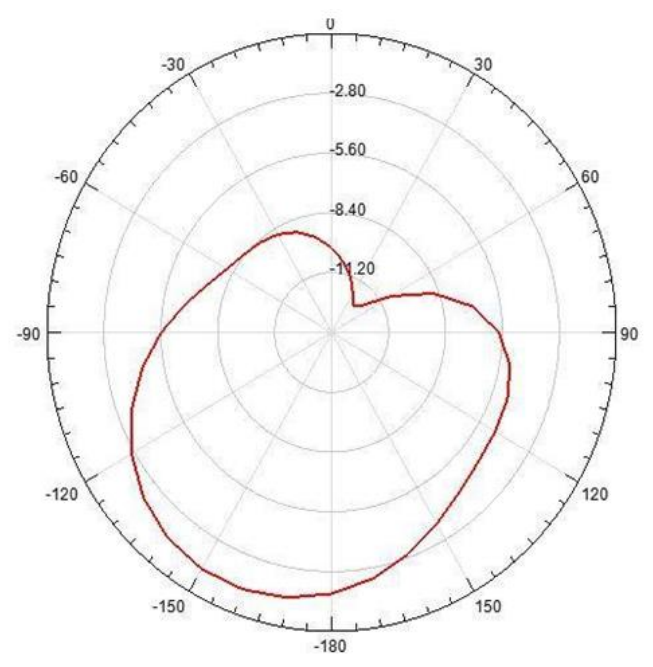

(b) $3.7 \mathrm{GHz}$

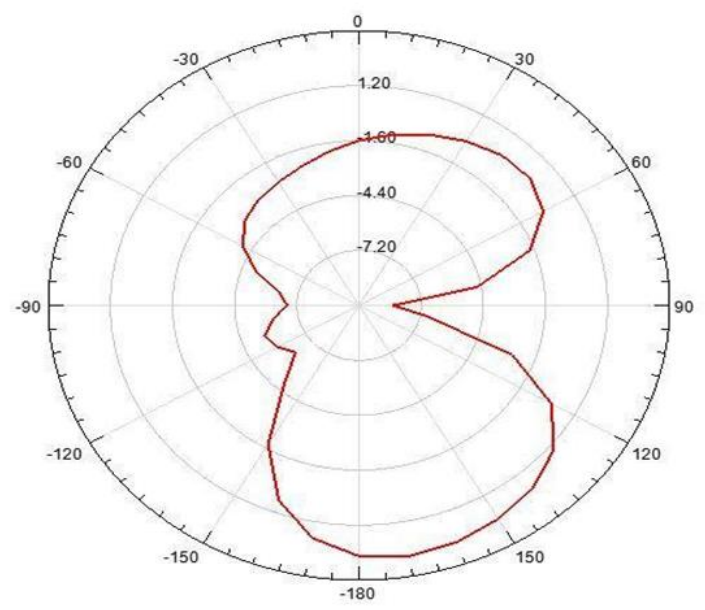

(C) $6.4 \mathrm{GHz}$

Figure 15. Radiation patterns of the proposed antenna with shorting pin

\section{Conclusion}

A novel compact triple band slot microstrip antenna for is presented the proposed antenna has a compact size of $60 \mathrm{mmx} 40 \mathrm{~mm}$ and it can effectively cover the 4G, WLAN Wi-MAX and Ultra Wide Band applications. In this paper, design of for small-size wide-bandwidth patch antennas has been presented. These designs combine the wideband U-slot and different substrate material and the addition of a shorting pin. Simulations were presented, and three of the simulated designs were verified by EM simulator. It was found that the dielectric constant of the material decreases bandwidth will increase. Good antenna performance and impedance matching can be realized by adjusting the probe position and the dimensions of the patch. 


\section{References}

[1] K. F. Lee, K. M. Luk, K. F. Tong, S. M. Shum, T. Huynh and R. Q. Lee, "Experimental and simulation studies of the coaxially fed U-slot rectangular patch antenna", Inst. Elect. Eng. Proc. -Microw. Antennas Propagat., vol. 144, (1997) October, pp. 354-358.

[2] T. Huynh and K. F. Lee, "Single-layer single-patch wideband microstrip antenna", Electron. Lett., vol. 31, no. 16, (1995), pp. 1310-1312.

[3] K. J. Babu, K. S. R. Krishna and L. P. Reddy, "A triband swastika shaped patch antenna with reduced mutual coupling for wireless MIMO systems", Journal of Electronics (China), SPRINGER, vol. 28, (2011) November, pp. 483-487.

[4] D. M. Pozar, "Microstrip Antennas", Proc. IEEE, vol. 80, no. 1, (1992) January, pp. 79-81.

[5] F. Caminita, S. Costanzo, G. DiMassa, G. Guarnieri, S. Maci, G. Mauriello and I. Venneri, "Reduction ofpatch antenna coupling by using a compact EBG formed by shorted strips with interlocked branchstubs", IEEE Antennas and Wireless Propagation Letters, vol. 8, (2009), pp. 811-814.

[6] K. J. Babu, K. S. R. Krishna and L. P. Reddy, "A Multi Slot Patch Antenna for 4G MIMO Communications", International Journal of Future Generation Communication and Networking, vol. 4, no. 2, (2011).

[7] S. C. Gao, L. W. Li, M. S. Leong and T. S. Yeo, "Analysis of an H-shaped patch antenna by using the FDTD Method", Progress in Electromagnetics Research, vol. 34, (2001), pp. 165-187.

[8] A. K. Shackelford, K. -F. Lee and K. M. Luk, "Design of Small-Size Wide-Bandwidth Microstrip-Patch Antennas", IEEE Antennas and Propagation MOQOZine, vol. 4-5, no. 1, (2003) February.

[9] L. H. Weng, Y. C. Guo, X. W. Shi and X. Q. Chen, "AN OVERVIEW ON DEFECTED GROUND STRUCTURE”, Progress In Electromagnetics Research B, vol. 7, (2008), pp. 173-189.

[10] K. Siakavara, "Methods to Design Microstrip Antennas for Modern Applications", Microstrip Antennas, N. Nasimuddin, (Ed.), ISBN: 978-953-307-247-0, InTech, (2011).

\section{Authors}

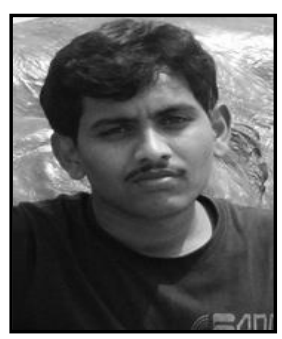

P. Kiran completed the B.Tech degree in Electronics and Communication Engineering in 2013 from the JNTU University, Kakinada. His areas of interest include Microstrip Antennas, MIMO Antennas, and Smart antennas for mobile communications. He is a member of ISTE.

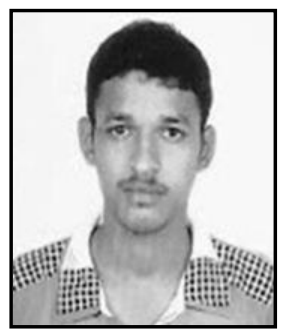

R. Chiramjeevi completed the B. Tech degree in Electronics and Communication Engineering in 2013 from the JNTU University, Kakinada. His areas of interest include Microstrip Antennas and Wireless communications. He is a member of ISTE

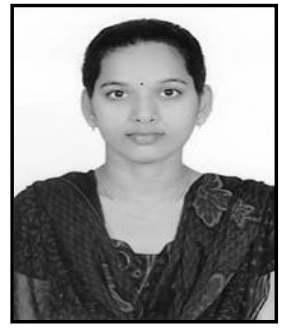

T. Chaitanya Reddy completed the B.Tech degree in Electronics and Communication Engineering in 2013 from the JNTU University, Kakinada. His areas of interest include Microstrip Antennas, MIMO Antennas. He is a member of ISTE. 


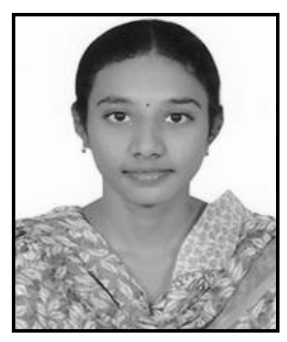

D. Sushma Sree completed the B.Tech degree in Electronics and Communication Engineering in 2013 from the JNTU University, Kakinada. His areas of interest include Microstrip Antennas, MIMO Antennas, and Embedded systems. He is a member of ISTE

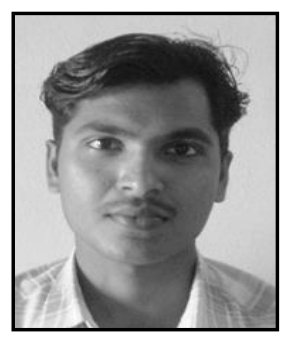

B. V. V. Ravindra Babu is working Assistant Professor in E.C.E Dept.,at St. Ann's College of Engineering \& Technology, Chirala, INDIA His areas of interest include MIMO Antennas, Wireless communications. He published 4 papers in reputed Journals $\mathrm{He}$ is a member of ISTE.

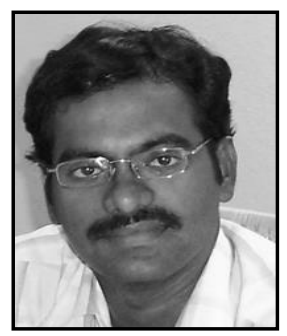

Dr. K. Jagadeesh Babu is working as Professor \& HOD in E.C.E Dept., at St. Ann's College of Engineering \& Technology, Chirala, INDIA. His areas of interest include Microwaves, Neural Networks, MIMO Antennas, Wireless communications. He published 20 papers in reputed Journals like WILEY, SPRINGER, ELSEVIER, etc... He is a member of ISTE and IAENG. 
International Journal of Energy, Information and Communications Vol.4, Issue 5 (2013) 